\title{
A Habitat Model for Fish Communities in Large Streams and Small Rivers
}

\author{
Mark B. Bain ${ }^{1}$ and Haifeng Jia ${ }^{2}$ \\ ${ }^{1}$ Department of Natural Resources, Cornell University, Ithaca, NY, 14853, USA \\ ${ }^{2}$ School of Environment, Tsinghua University, Beijing 100084, China \\ Correspondence should be addressed to Haifeng Jia, jhf@tsinghua.edu.cn \\ Received 3 August 2011; Revised 11 January 2012; Accepted 25 January 2012 \\ Academic Editor: L. M. Chu
}

Copyright (C) 2012 M. B. Bain and H. Jia. This is an open access article distributed under the Creative Commons Attribution License, which permits unrestricted use, distribution, and reproduction in any medium, provided the original work is properly cited.

Habitat has become one of the fundamentals for managing the environment. We report on synthesis of 30 habitat models for fish species that inhabit large streams and small rivers. Our protocol for integration of many species-level habitat models was to form a robust, general model that reflected the most common characteristics of the reviewed models. Eleven habitat variables were most commonly used in habitat models, and they were grouped by water quality, reproduction, and food and cover. The developed relations defined acceptable and optimal conditions for each habitat variable. Water quality variables were mid-summer water temperature, dissolved oxygen, $\mathrm{pH}$, and turbidity. Other structural habitat variables were identified: riffle and pool velocity, riffle depth, and percent of the stream area with cover and pools. We conclude that it is feasible to consolidate species-level habitat models for fish that inhabit the same waterway type. Given the similarity among species models, our specification set will closely approximate the needs and optimal conditions of many species. These eleven variables can serve as design specifications for rehabilitating streams and small rivers in human dominated settings.

\section{Introduction}

Habitat is a common basis for impact assessments, resource inventories, species management, and mitigation planning. When all habitats covering life cycle for a species is available that signals species presence. When habitat conditions match the preferred range, then expectations species will occur in high abundance. Specifying a niche is equivalent to defining habitat conditions $[1,2]$ that allow a species to persist in space and time. Habitat can be defined in clear and quantitative terms by linking to a specific species that has tolerance and habitat requirements. Habitat can be much more stable than population properties and is required for species conservation. That is why habitat is a tangible resource that can be measured and modeled for considering future changes. Thus, habitat has become one of the most important concepts for managing the environment.

Quantification of habitat for impact assessment motivated habitat modeling. The U.S. Fish and Wildlife Service developed habitat-based impact evaluation procedures
$[33,34]$, and they are in use today. The habitat evaluation procedures are composed of the habitat suitability index (HSI) models to identify tolerable and quality habitat conditions for species. The second part is accounting procedures to quantify habitat impacts of proposed developments. The HSI models are in a common format with an index between zero and 1 with zero designating no habitat and 1 being optimal habitat. These HSI models were constructed for many and varied species, and over 150 HSI models have been developed in agency documents [35]. In this paper, we report on synthesis HSI models for fish species that inhabit large streams and small rivers. We explored whether these multispecies HSI models serve as a good habitat definition that the species which often cooccur may have similar habitat needs. While the HSI models are for North American fish species, they span many species and may define conditions for river rehabilitation for novel river environments like urban waterways. Increasingly, waterways are being rehabilitated in human dominated settings that are not possible to return to natural conditions. Without a 


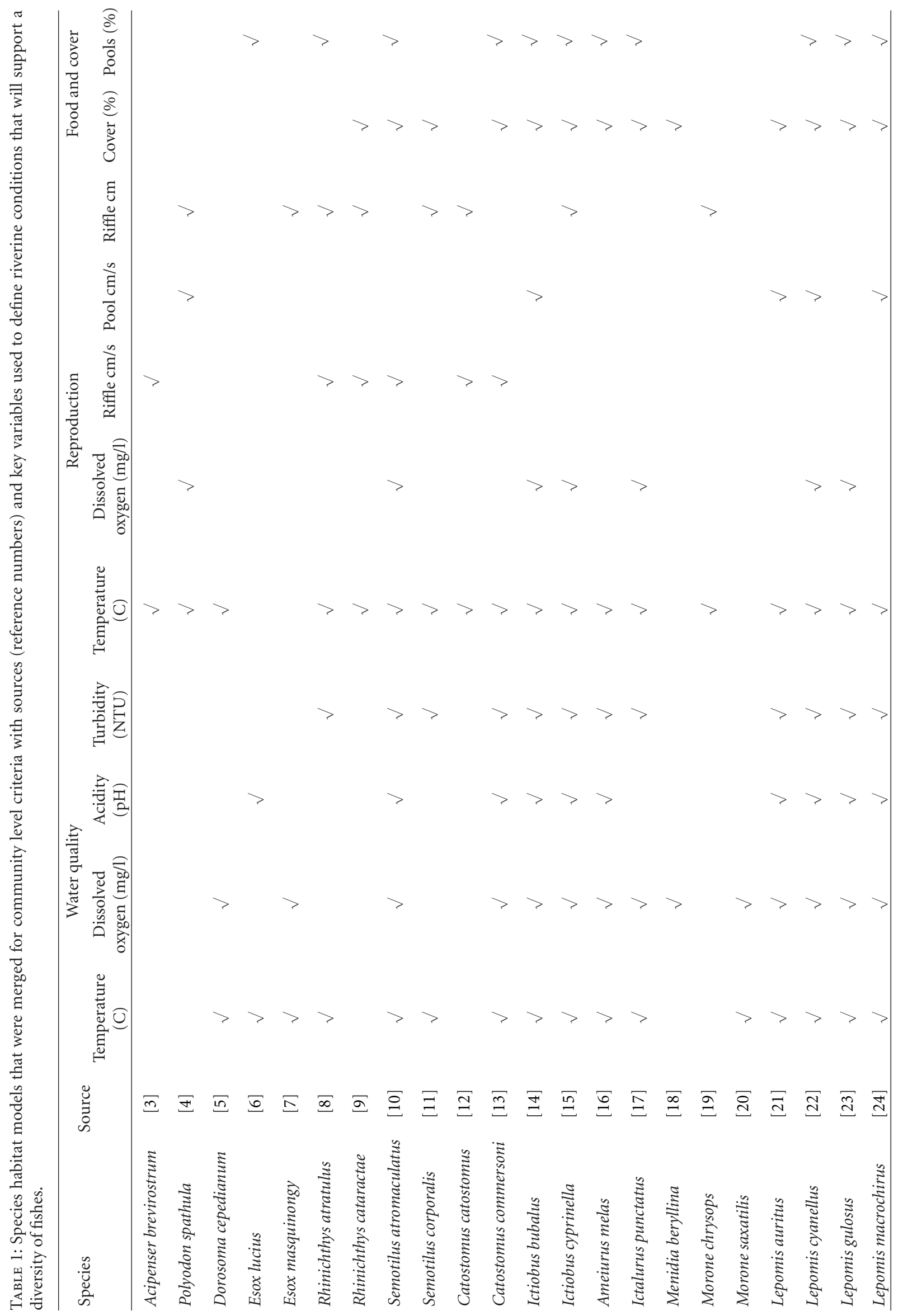




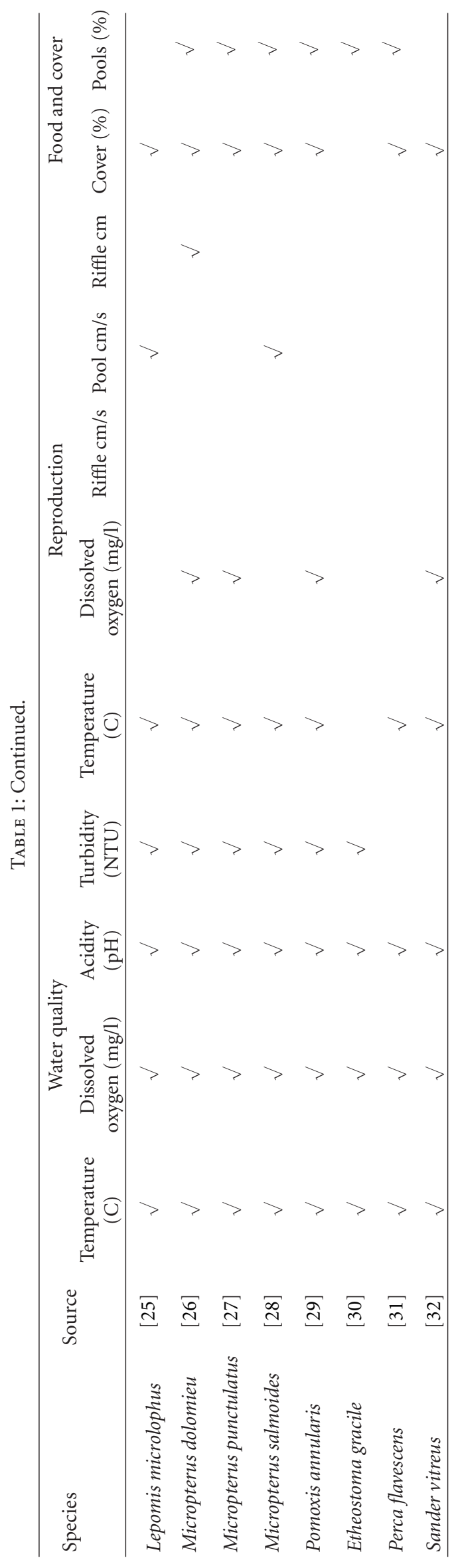


TABLE 2: Habitat definitions and optimal ranges for 11 variables that serve as specifications for rehabilitating streams and small rivers. The manner that species model variables were consolidated and the key to plots are provided in Figure 1.

\begin{tabular}{|c|c|c|c|c|}
\hline Parameter & $\begin{array}{c}\text { Figure } 1 \\
\text { panel }\end{array}$ & $\begin{array}{c}\text { Habitat } \\
\text { range }\end{array}$ & $\begin{array}{c}\text { Optimal } \\
\text { range }\end{array}$ & Synthesis comments \\
\hline $\begin{array}{l}\text { Mean water } \\
\text { temperature }(\mathrm{C}) \text { in } \\
\text { mid-summer. }\end{array}$ & (a) & $12-33$ & $23-28$ & $\begin{array}{l}\text { Most models specified mean temperatures forming a } \\
\text { habitat and optimal range. The breakpoints were } \\
\text { averaged. Most species were within the habitat range and } \\
\text { approximated the optimal range. }\end{array}$ \\
\hline
\end{tabular}

Minimum dissolved oxygen $(\mathrm{mg} / \mathrm{l})$ in

mid-summer.

Annual acidity

(hydrogen ion

concentration, $\mathrm{pH})$.

(c)

$4.7-9.8$

$6.6-8.6$

Turbidity

(nephelometric

turbidity units,

NTU), maximum

monthly mean.

Mean water

temperature $(\mathrm{C})$

during most common

reproduction season,

spring.

Dissolved oxygen

(mg/l) during the

spring reproduction

season.

Mean current velocity

$(\mathrm{cm} / \mathrm{s})$ in riffle

habitats during the

spring reproduction

season.

Mean current velocity

$(\mathrm{cm} / \mathrm{s})$ in pool

habitats during the

spring reproduction

season.

Maximum riffle water depth $(\mathrm{cm})$ during the spring

$12-28$

$17-22$

reproduction time.

Portion (\%) of waterway with cover for fish and food organisms.

Portion (\%) of waterway that is slow water: pools and backwaters.
All models showed a rise in quality from about $1 \mathrm{mg} / \mathrm{l}$ as a minimum to an optimal range without a maximum. Averages defined breakpoints. Some species went down to zero, which was unsuitable. There was much consistency for dissolved oxygen.

The models specified similar values for habitat and optimal ranges. The breakpoints were averaged. There was good consistency for $\mathrm{pH}$.

Models indicated declining quality with increased turbidity beyond an optimal range. Average were used to define the optimal and tolerable levels. Conversion of measurements and statistics revealed a consistent habitat definition and optimal range for most species.

Most models specified mean temperatures forming a habitat and optimal range during the spring fish reproduction season. Most species were within the habitat range. All species had a dome-shape-relation between habitat quality and temperature. Averages defined breakpoints.

All models showed a rise in quality from $1.5 \mathrm{mg} / \mathrm{l}$ as a minimum to an optimal range without a maximum. Averages defined breakpoints. There was consistency for dissolved oxygen.

Models defined a habitat and optimal range for riffle velocity for spawning and young during the spring. The breakpoints were averaged. There was some variability in in riffle velocities, but the habitat and optimal range approximated most of the species.

Models defined a habitat and optimal range for pool velocity for spawning and young during the spring. Averages were used to define the range. There was some variability in pool velocities, but the habitat and optimal range approximated most of the species.

Models varied in specifying water depth for spawning and larval rearing. The models specifying water depth range were averaged. There was some variability in riffle depths but the habitat and optimal overlapped most species models.

Models defined a habitat and optimal percentage of area with cover. Average was used to define breakpoints. There were many species that had this habitat variable and most HSI models were similar to the ranges.

Models defined a habitat and optimal range of area composed of slow and standing water at common flows. The breakpoints were averaged. The optimal habitat condition included the range for most species. 


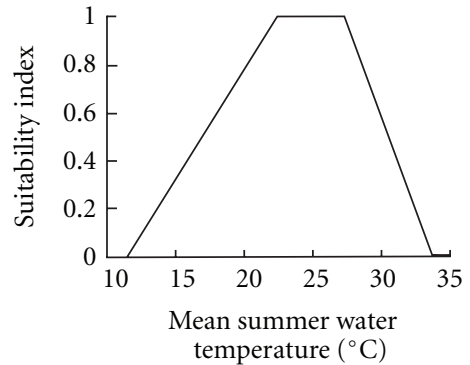

(a)

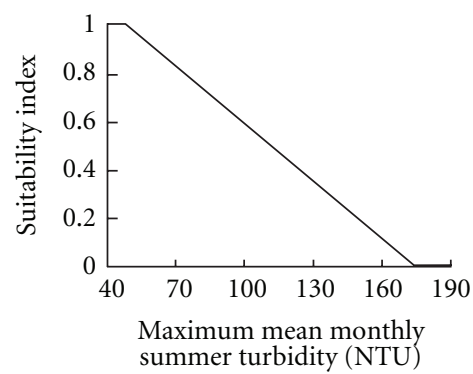

(d)

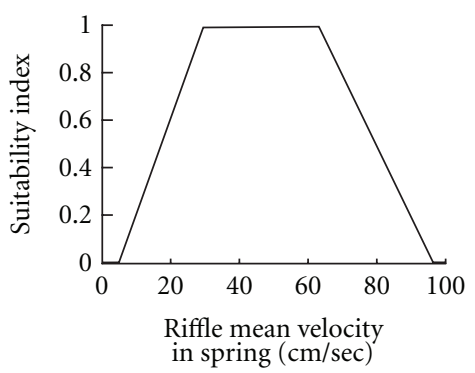

(g)

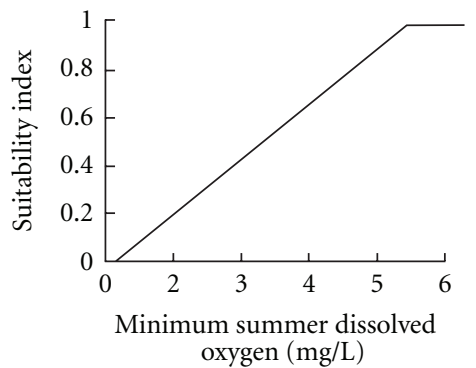

(b)

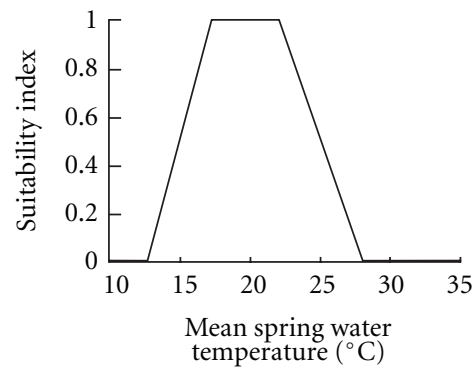

(e)

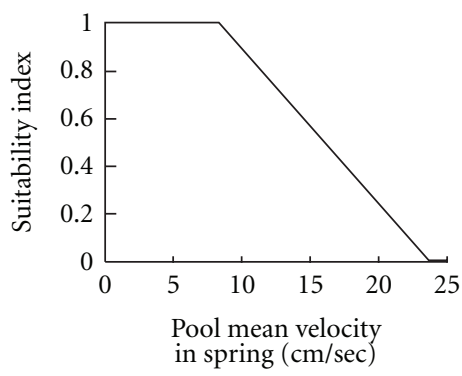

(h)

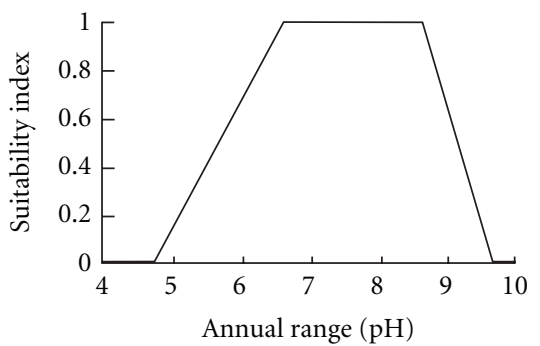

(c)

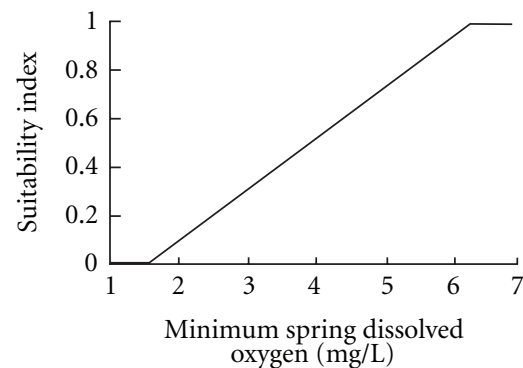

(f)

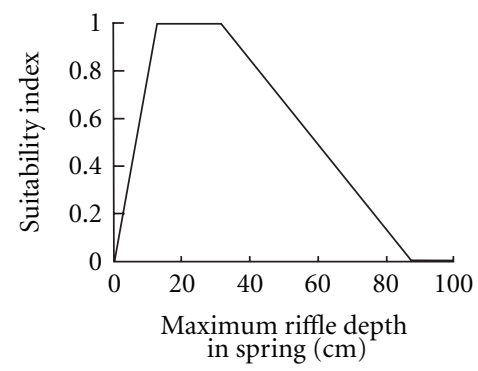

(i)

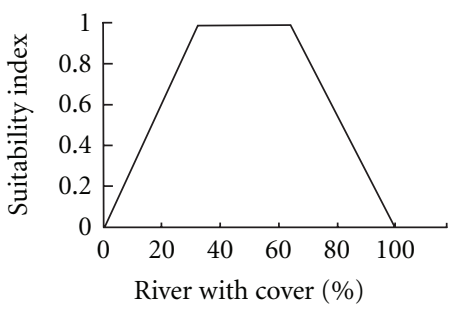

(j)

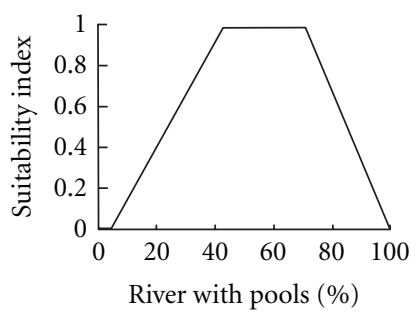

(k)

FIgURE 1: Suitability index plots of 11 variables shown with a tolerable range ( 0 points on the $Y$-axis) and optimal range ( 1 values on the $Y$-axis) for each variable. Panel plots are cross referenced in Table 2 where more detailed definitions of the variables are provided.

natural conditions to serve as vision, the synthesis of many fish species habitat needs may provide guidance to designing rehabilitation.

\section{Methods}

Our protocol for synthesizing the HSI models proceeded in a manner to form a robust, general model that reflected the most common characteristics of the reviewed models. We included information about where it could be combined to produce model characteristics based on the largest number of review models. Our general synthesis approach was selected to produce a community-level model that captures typical stream and river characteristics that support a wide range of fishes.

Thirty species-level HSI models were identified from a review of those published by the U.S. Fish and Wildlife Service [35] for fish that inhabit large streams and small rivers (nonnavigable rivers, Table 1). The collection of fish do not include coldwater fishes (salmonidae) that commonly 
inhabit mountain streams. The 30 HSI models also did not include anadromous and estuarine fishes that are of coastal orientation. The HSI models included the dominant flowing fish families (Cyprinidae, Catostomidae, Centrarchidae, and Percidae) and others (e.g., Ictaluridae and Esocidae) inhabiting interior, low elevation flowing waters in North America. Thus a broad range of fish types inhabiting streams and rivers, across the North America were included.

We started by making a list of all variables for the 30 HSI models. Unique and rare variables limited to one or a few species were not included. We organized the variables under components that were assigned in the HSI models. The variables in the HSI models were all grouped in three components: water quality, reproduction, and food and cover. Water quality variables were often used in the collection of HSI models. Water temperature and dissolved oxygen were also listed under reproduction component with different values: cooler spring months and sensitivity for high oxygen by eggs and newly hatched fish. Under reproduction component, riffle and pool velocity and riffle depth were sporadic but common in the HSI models. For the food and cover component, the percent of the stream area with cover and pools were used in most of the HSI models. Cover is a term for materials such as boulders, logs, sticks, and aquatic vegetation that provide refugee for aquatic organisms in both food and small fish. Added surfaces provides colonizations sites for macroinvertebrates.

Next, we review each variable and made a list of the breakpoints (change points) values defining shape and tolerable range. Most variables had the same shape of the relation between habitat quality. Means were often used for the consolidated breakpoints. That was reported in a table because each habitat variable was different. We aimed for synthesized relations to identify common criteria that define acceptable and optimal habitat conditions for each variable. The final step was plotting the curves for key variables in the form of HSI models.

\section{Results}

From the review of all variables in the 30 HSI models, we identified 11 variables that were most commonly used to define stream and river habitat (Table 1). Among the water quality variables, there was consistency for mid-summer water temperature and dissolved oxygen ranges that define habitat and optimal conditions. Summer warmth often produces the most stressful temperatures and the lowest dissolved oxygen of the year. Most species had ranges that consistent designated habitat and optimal ranges reported in Table 2. Annual average $\mathrm{pH}$ was very consistent across species. Turbidity varied in reported measurements, and we converted of measurements to nephelometric turbidity units (NTU). Conversion of measurements and statistics indicated that there were consistency across species and a common form to the turbidity relation with habitat quality.

Temperature and dissolved oxygen are also listed again under reproduction component. The water temperature was cooler for the spring, and this was common reproductive time for stream fishes (Table 2). Dissolved oxygen was higher for the habitat and optimal ranges because eggs needed more oxygen in the water. Riffles are defined as shallow areas with $1-4 \%$ gradient with small hydraulic turbulence over coarse substrate causing small ripples and waves [36]. Often fish put eggs in riffles, because current is not that fast, flow of water of over eggs promotes high oxygen. After hatching many fishes they move to pools and backwaters. Pools are defined [36] as aquatic habitats with a gradient less than $1 \%$ that is normally deeper and wider than riffle or turbulent areas. Mean water velocity in pools and backwaters are important for retaining newly hatched fish and providing productive nursery conditions. The habitat and optimal range riffle velocities and depths and pool velocities are given in Table 2. Pools and backwaters trap floating organisms that small fish use for feed.

The synthesized variables were plotted in Figure 1 on the same habitat suitability scale as the reviewed HSI models. Habitat and optimal ranges were used to plot Figure 1, and the methods used for synthesis are reviewed in Table 2. This table also defines each variable and presents the numbers of the habitat and optimal range shown in Figure 1 plots. The generalized nature of the synthesized HSI model will satisfy or approximate the needs of most fish species.

\section{Discussion}

We identified 30 species-level HSI models that focus on fishes that use large streams and small rivers. These fish often cooccur and have similar habitat needs. We found a common similarity among the fish species, and they had similar variables and habitat and optimal ranges. Thus it was feasible to construct an integrated model for a group of fish that occupy the same general habitat type. About half of the variables in the reviewed models pertained to water quality and about half specified physical conditions. They were grouped as water quality, reproduction, and food and cover. Overall, we view our synthesized model closely parallel to many of the riverine HSI models we included in the analysis. We conclude that it is feasible to consolidate species level habitat needs for fish that inhabit the same waterway type.

The plots of the 11 variables (Figure 1) use a suitability index scale, which allows definition of acceptable habitat and yields ratings of the relative benefit of different values. Eight variables have a clear tolerable range ( $>0$ values on the $Y$ axis), which defines habitat needed for fish support. These eight plots also have an optimal range for each variable, which is an estimate of the best conditions for fish support. Three variables have an undefined optimal range implying that the optimal conditions extended beyond the plot over the feasible range of the variable. Two of these were for dissolved oxygen, and they indicate that higher dissolved oxygen would remain in the optimal range. The reverse pattern is for turbidity and specifies that clearer water is optimal and will remain optimal. These forms of variable relations to habitat quality are the same format in the 
HSI models and have been used for assessing impacts and mitigation actions for more than two decades.

Interest and efforts are increasing on improving environments that are in human-dominated settings $[37,38]$ which cannot be converted to natural conditions. These eleven variables can serve as design specifications for rehabilitating streams and small rivers in combination with definitions for riffles, pool, and backwaters. They can be used individually or as a set to design criteria to improve a waterway for fish community support. Alternative designs can be compared with suitability index values from the plots to compare rehabilitation options. Our generalized set of specifications can support a diversity of fish species. Finally, given the similarity among species models, our specification set will closely approximate the needs and optimal conditions of many species.

An established fish community is a convincing indicator of healthy river and the success of river rehabilitation. In many countries, along with the urban development and economical growth, the ecological rehabilitation of polluted urban rivers and other streams have become a major concern of government officers, conservation experts, and the public. The research can provide design specifications to support fish communities, and that will add a biological dimension to current river rehabilitation efforts.

\section{Disclosure}

The paper was initiated during a visiting scholar stay at Department of Environmental Science and Engineering, Tsinghua University, in Beijing China. The need emerged for this work from discussions at a session (Environmental Flow in Water Righting) at the 2010 Ecohydraulics Conference in Seoul, South Korea organized by Zhongjing Wang, Zhaoyin Wang, and Zhenzhen Ma.

\section{References}

[1] H. R. Pulliam, "On the relationship between niche and distribution,” Ecology Letters, vol. 3, no. 4, pp. 349-361, 2000.

[2] A. H. Hirzel and G. Le Lay, "Habitat suitability modelling and niche theory," Journal of Applied Ecology, vol. 45, no. 5, pp. 1372-1381, 2008.

[3] J. H. Crance, "Habitat suitability index models and instream flow suitability curves: shortnose sturgeon," Biological Report 82(10.129), U. S. Fish and Wildlife Service, Washington, DC, USA, 1986.

[4] W. A. Hubert, S. H. Anderson, P. D. Southall, and J. H. Crance, "Habitat suitability index models and instream flow suitability curves: paddlefish," Tech. Rep. FWS/OBS-82/10.80, U. S. Fish and Wildlife Service, Washington, DC, USA, 1984.

[5] K. L. Williamson and P. C. Nelson, "Habitat suitability index models and instream flow suitability curves: gizzard shad," Biological Report 82(10.112), U. S. Fish and Wildlife Service, Washington, DC, USA, 1985.

[6] P. D. Inskip, "Habitat suitability index models: northern pike," Tech. Rep. FWS/OBS-82/10.17, U. S. Fish and Wildlife Service, Washington, DC, USA, 1982.
[7] M. F. Cook and R. C. Solomon, "Habitat suitability index models: muskellunge," Biological Report 82(10.148), U. S. Fish and Wildlife Service, Washington, DC, USA, 1987.

[8] J. G. Trial, J. G. Stanley, M. Batcheller, G. Gebhart, O. E. Maughan, and P. C. Nelson, "Habitat suitability information: blacknose dace," Tech. Rep. FWS/OBS-82/10.41, U. S. Fish and Wildlife Service, Washington, DC, USA, 1983.

[9] E. A. Edwards, H. Li, C. B. Schreck, and G. Gebhart, "Habitat suitability index models: longnose dace," Tech. Rep. FWS/OBS-82/10.33, U. S. Fish and Wildlife Service, Washington, DC, USA, 1983.

[10] T. E. McMahon, "Habitat suitability index models: creek chub," Tech. Rep. FWS/OBS-82/10.4, U. S. Fish and Wildlife Service, Washington, DC, USA, 1982.

[11] J. G. Trial, C. S. Wade, J. G. Stanley, and O. E. Maughan, "Habitat suitability information: fallfish," Tech. Rep. FWS/OBS82/10.48, U. S. Fish and Wildlife Service, Washington, DC, USA, 1983.

[12] E. A. Edwards, "Habitat suitability index models: longnose sucker," Tech. Rep. FWS/OBS-82/10.35, U. S. Fish and Wildlife Service, Washington, DC, USA, 1983.

[13] K. A. Twomey, K. L. Williamson, and P. C. Nelson, "Habitat suitability index models and instream flow suitability curves: white sucker," Tech. Rep. FWS/OBS-82/10.64, U. S. Fish and Wildlife Service, Washington, DC, USA, 1984.

[14] E. A. Edwards and K. Twomey, "Habitat suitability index models: smallmouth buffalo," Tech. Rep. FWS/OBS-82/10.13, U. S. Fish and Wildlife Service, Washington, DC, USA, 1982.

[15] E. A. Edwards, "Habitat suitability index models: bigmouth buffalo," Tech. Rep. FWS/OBS-82/10.34, U. S. Fish and Wildlife Service, Washington, DC, USA, 1983.

[16] R. J. Stuber, "Habitat suitability index models: black bullhead," Tech. Rep. FWS/OBS-82/10.14, U. S. Fish and Wildlife Service, Washington, DC, USA, 1982.

[17] T. E. McMahon and J. W. Terrell, "Habitat suitability index models: channel catfish," Tech. Rep. FWS/OBS-82/10.2, U. S. Fish and Wildlife Service, Washington, DC, USA, 1982.

[18] M. P. Weinstein, "Habitat suitability index models: inland silverside," Biological Report 82(10.120), U. S. Fish and Wildlife Service, Washington, DC, USA, 1986.

[19] K. Hamilton and P. C. Nelson, "Habitat suitability index models and instream flow suitability curves: white bass," Biological Report 82(10.89), U. S. Fish and Wildlife Service, Washington, DC, USA, 1984.

[20] J. H. Crance, "Habitat suitability index models and instream flow suitability curves: inland stocks of striped bass," Tech. Rep. FWS/OBS-82/10.85, U. S. Fish and Wildlife Service, Washington, DC, USA, 1984.

[21] J. M. Aho and J. W. Terrell, "Habitat suitability index models and instream flow suitability curves: redbreast sunfish," Biological Report 82(10.119), U. S. Fish and Wildlife Service, Washington, DC, USA, 1986.

[22] R. J. Stuber, G. Gebhart, and O. E. Maughan, "Habitat suitability index models: green sunfish," Tech. Rep. FWS/OBS$82 / 10.15$, U. S. Fish and Wildlife Service, Washington, DC, USA, 1982.

[23] T. E. McMahon, G. Gebhart, O. E. Maughan, and P. C. Nelson, "Habitat suitability index models and instream flow suitability curves: warmouth," Tech. Rep. FWS/OBS-82/10.67, U. S. Fish and Wildlife Service, Washington, DC, USA, 1984.

[24] R. J. Stuber, G. Gebhart, and O. E. Maughan, "Habitat suitability index models: bluegill,” Tech. Rep. FWS/OBS-82/10.8, U. S. Fish and Wildlife Service, Washington, DC, USA, 1982. 
[25] K. A. Twomey, G. Gebhart, O. E. Maughan, and P. C. Nelson, "Habitat suitability index models and instream flow suitability curves: redear sunfish," Tech. Rep. FWS/OBS-82/10.79, U. S. Fish and Wildlife Service, Washington, DC, USA, 1984.

[26] E. A. Edwards, G. Gebhart, and O. E. Maughan, "Habitat suitability information: smallmouth bass," Tech. Rep. FWS/OBS82/10.36, U. S. Fish and Wildlife Service, Washington, DC, USA, 1983.

[27] T. E. McMahon, G. Gebhart, O. E. Maughan, and P. C. Nelson, "Habitat suitability index models and instream flow suitability curves: spotted bass," Tech. Rep. FWS/OBS-82/10.72, U. S. Fish and Wildlife Service, Washington, DC, USA, 1984.

[28] R. J. Stuber, G. Gebhart, and O. E. Maughan, "Habitat suitability index models: largemouth bass," Tech. Rep. FWS/OBS$82 / 10.16$, U. S. Fish and Wildlife Service, Washington, DC, USA, 1982.

[29] E. A. Edwards, D. A. Krieger, G. Gebhart, and O. E. Maughan, "Habitat suitability index models: white crappie," Tech. Rep. FWS/OBS-82/10.7, U. S. Fish and Wildlife Service, Washington, DC, USA, 1982.

[30] E. A. Edwards, M. Bacteller, and O. E. Maughan, "Habitat suitability index models: slough darter," Tech. Rep. FWS/OBS$82 / 10.9$, U. S. Fish and Wildlife Service, Washington, DC, USA, 1982.

[31] D. A. Krieger, J. W. Terrell, and P. C. Nelson, "Habitat suitability information: yellow perch,” Tech. Rep. FWS/OBS-82/10.55, U. S. Fish and Wildlife Service, Washington, DC, USA, 1983.

[32] T. E. McMahon, J. W. Terrell, and P. C. Nelson, "Habitat suitability information: walleye," Tech. Rep. FWS/OBS-82/10.56, U. S. Fish and Wildlife Service, Washington, DC, USA, 1984.

[33] U. S. Fish and Wildlife Service, "Habitat as a basis for environmental assessment," in Ecological Services Manual 101, U. S. Fish and Wildlife Service, Washington, DC, USA, 1980.

[34] U. S. Fish and Wildlife Service, "Habitat evaluation procedures (HEP)," in Ecological Services Manual 102, U. S. Fish and Wildlife Service, Washington, DC, USA, 1980.

[35] U. S. Geological Survey, "Habitat suitability index models digital library," Lafayette, Louisana: USGS National Wetlands Research Center, http://www.nwrc.usgs.gov/wdb/pub/ hsi/hsiintro.htm.

[36] N. B. Armantrout, Glossary of Aquatic Habitat Inventory Terminology, American Fisheries Society, Bethesda, Md, USA, 1998.

[37] M. Palmer, E. Bernhardt, E. Chornesky et al., "Ecology for a crowded planet," Science, vol. 304, no. 5675, pp. 1251-1252, 2004.

[38] P. Kareiva, S. Watts, R. McDonald, and T. Boucher, "Domesticated nature: shaping landscapes and ecosystems for human welfare," Science, vol. 316, no. 5833, pp. 1866-1869, 2007. 

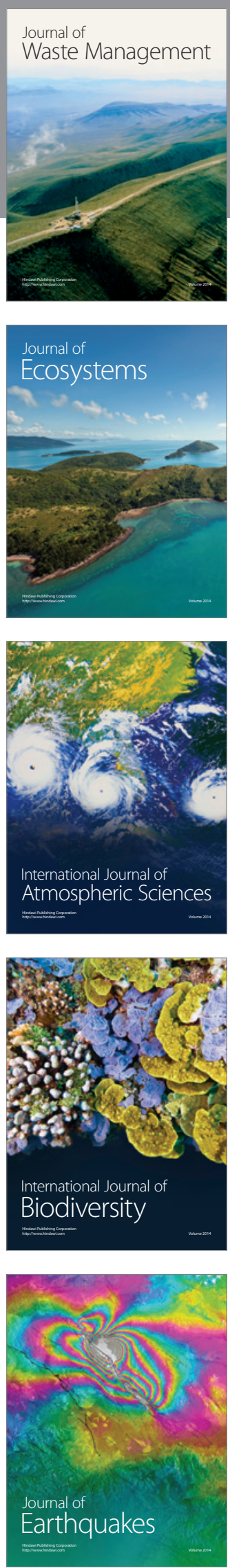
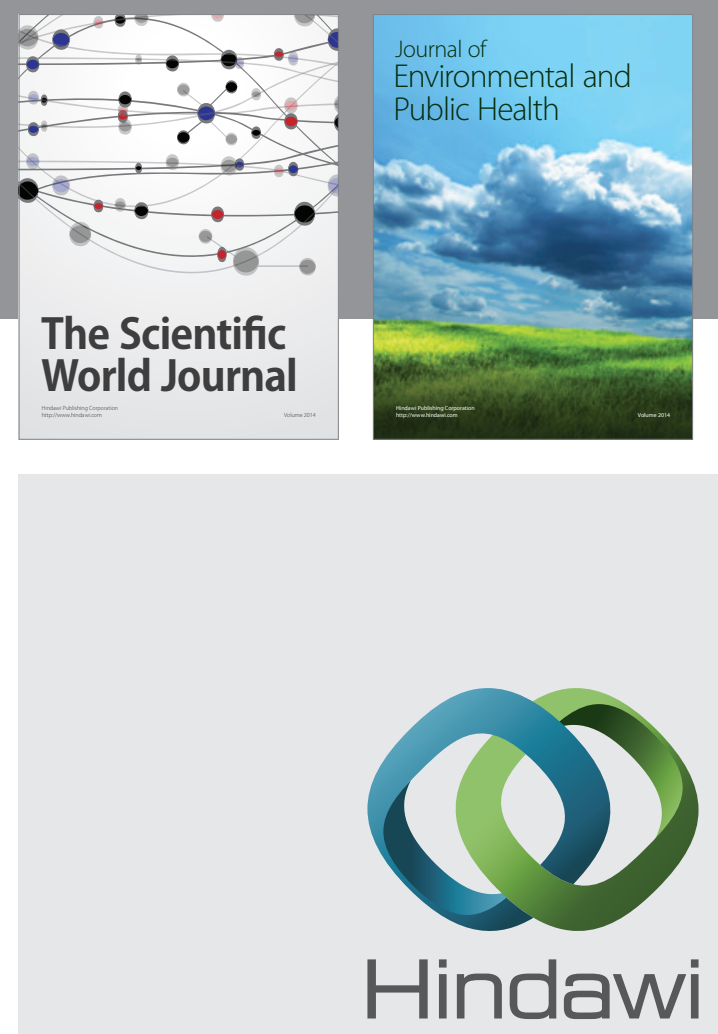

Submit your manuscripts at

http://www.hindawi.com
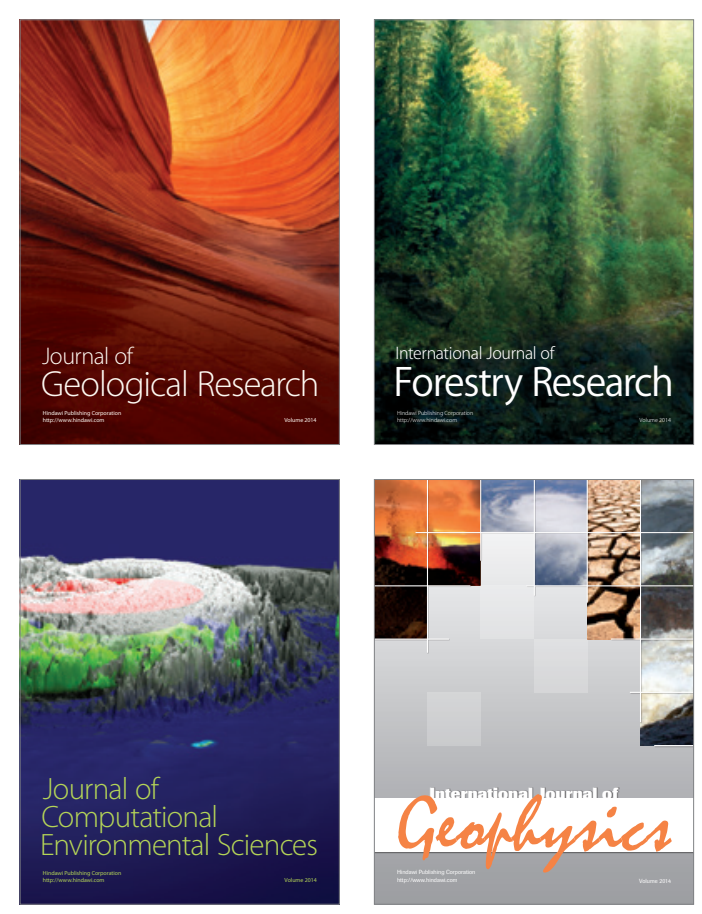
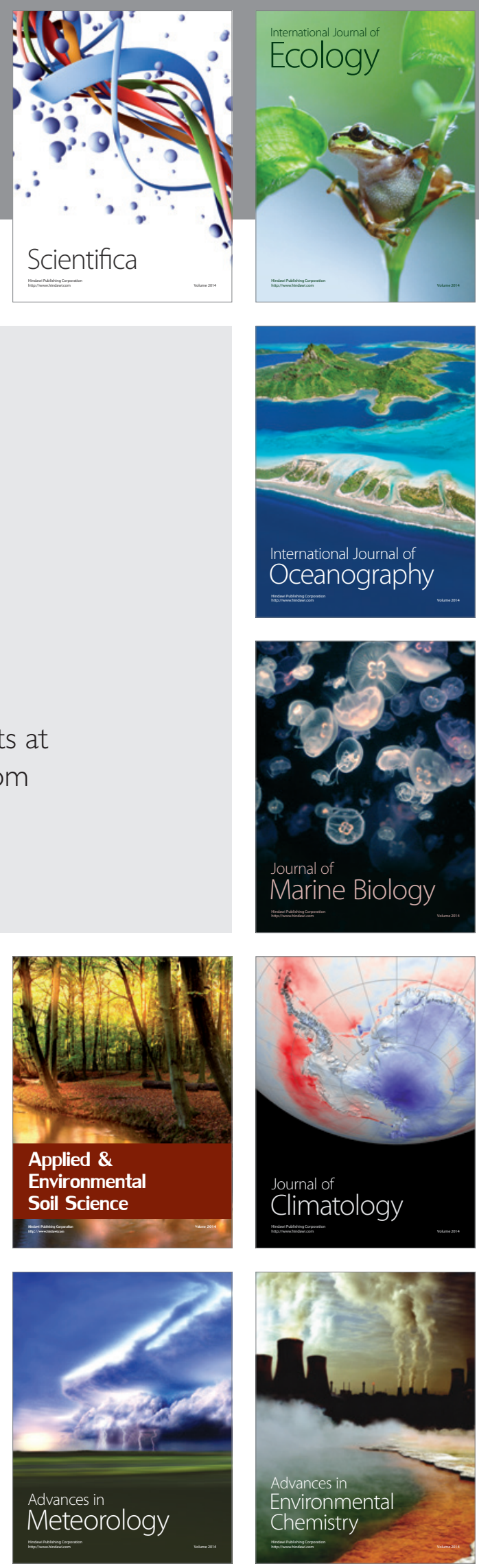